\title{
Multi-purposeful Application of Geospatial Data
}

\author{
Chattopadhyay Nabansu, Chandras Swati and \\ Tidke Nivedita
}

Additional information is available at the end of the chapter

http://dx.doi.org/10.5772/intechopen.74217

\begin{abstract}
Agriculture is the backbone of the Indian economy. Any changes in weather and climate in short term as well as long- term adversely affect the agricultural productivity and the production of food grain production. In order to minimise the adverse impact of weather and climate on crops, the use of agrometeorological information and agromet services has already been proved to be highly beneficial. Agrometeorological services rendered by India Meteorological Department (IMD), Ministry of Earth Sciences, are a step to contribute to weather information-based crop/livestock management strategies and operations dedicated to enhance crop production and food security. IMD is operating a project 'Gramin Krishi Mausam Sewa' (GKMS) with an objective to serve the farming community at different parts of the country. Different states of technologies including the application of geospatial technology are being used in India for further refinement of the Agromet Advisory Services. The application of geospatial technology in generating agrometeorological information and products is very necessary for preparing needbased advisories at a high-resolution scale for the farmers in the country. In this chapter, elaborate discussion has been made on how the Geographical Information System (GIS) is being used for generating information and products using ground observations as well as satellite observations.
\end{abstract}

Keywords: geospatial technology, agromet products, agrometeorology

\section{Introduction}

Weather and climate play an important role in agricultural production. It has a profound influence on crop growth, development and yields; on the incidence of pests and diseases; on water needs; and on fertiliser requirements. Weather aberrations may cause physical damage 
to crops and soil erosion. The provision of need-based climate information to farmers can support the management of agricultural resources (land, water and genetic resources). India Meteorological Department (IMD), Ministry of Earth Sciences (MoES), is operating Gramin Krishi Mausam Seva (GKMS) project at the district level in India, which represents a small step towards agriculture management in rhythm with weather and climate variability, leading to weather proofing for farm production. In order to minimise the adverse impact of malevolent weather, GKMS project provides a very special kind of inputs to the farmer as advisories that can make a tremendous difference to the agriculture production. The primary role of combating the negative impact of extreme events under the Agromet Advisory Services (AAS) is to find out the basic requirement to generate ways and means of adjusting crop cultivation plans/practices depending on the time of occurrence of the extreme events. Farmers are using these advisories for sowing and transplantation of crops, fertiliser application, predictions regarding pests and diseases and measures to control them, weeding/thinning, irrigation (quantities and timing) and harvest of crops.

Under the GKMS project, a number of activities were carried out during the last couple of years particularly in the generation of weather forecast, agromet advisories and its dissemination, capacity building, awareness, outreach, and so on in collaboration with 130 Agromet Field Units (AMFUs) located at State Agricultural Universities, Institutes of Indian Council of Agricultural Research (ICAR), Indian Institute of Technology (IITs) and also other collaborating organisations. At present, quantitative weather forecast in medium-range scale is being used in the preparation of agromet advisories at the district level for the farmers in the country. In addition to that, state composite and national level Agromet Advisory Service advisories are also prepared for state and national levels for planners and other users in macro-level planning and particularly under contingent plan. Efforts have also been made for the preparation of accurate medium-range weather forecast by value addition from Regional Meteorological Centres (RMCs)/Meteorological Centres (MCs). To help the farmers to cope with climate risks and uncertainties and also effectively use seasonal to inter-annual climate forecasts, IMD in collaboration with Central Research Institute for Dryland Agriculture, Hyderabad, also issued AAS Bulletins based on Extended Range Weather Forecast and Monthly Weather Forecast during southwest monsoon 2017 to fulfil the needs of different users including planners at state and national levels and farmers.

Among others, the generation and use of different agromet information and products are important initiatives to deliver crop- and location-specific agromet advisories to the farmers in the country. Here, GIS has an important role to play. Agrometeorological products are derived parameters from meteorological/agrometeorological or other interdisciplinary information. It deals with the application of weather- and climate-derived information in agricultural management. Timely availability and appropriate use of this information are vital for successful farming operations. These products serve as an important step for improving the agromet advisories and ultimately in the quality of bulletin. The first and foremost consideration is user requirements. Thus, agromet products are crop and location specific. At present, integrated approaches are being adopted by combining ground data, satellite data along with the high-resolution models and GIS technology to provide crop and location specific even at 
district/sub-district level agromet advisories for meeting individual demand of the farmers. In this chapter, an elaborate discussion has been made regarding how the GIS is being used and what are the future plans to improve the services for the farmers in the country by exploiting the modern geospatial technology.

\section{Application of GIS in agrometeorology}

GIS is extensively used in modern science of operational agrometeorology. Under GIS platform, diverse data sources like real-time weather data including climatological data, land surface data and satellite data are fed into advanced system along with the algorithms for the visualisation of information and also products.

A GIS provides an organised method of storing spatial data. It stores the characteristics of features (the attribute component) in a database and then links the attributes to features (the spatial component) that it displays on a map. According to Refs. [1, 2], technology is an expansion of Cartographic Science, which takes advantage of computer science technologies, enhancing the efficiency and analytic power of traditional methodologies.

In a GIS, all the information can be linked and processed simultaneously, thus creating a syntactical expression of the changes induced in the system by the variation of a parameter. Using GIS improves data integration and usability, spatial analysis, and increases potential for broader applications. GIS could also make weather and climate information more usable in different allied fields of meteorological community. GIS is an essential tool to understand complex processes at different scales: local, regional and global. It is being extensively used in the science of agrometeorology. In GIS, the information coming from different disciplines and sources, that is, from traditional or digital maps, databases and remote-sensing, can be combined in models that simulate the behaviour of complex systems. Some common applications are relative to the control of industrial cycles, the simulation of urban and natural systems, the evaluation of specific procedures and the analysis of environmental impact (Refs. [3-5]).

Under the climate service programme, GIS is used extensively using the long period data. It also helps in the development of climate service tools for different sectors like agriculture, health, disaster risk reduction, and so on. These days, GIS is also used in the visualisation of weather pattern and other areas of interests of the common man. Most of the feature of GIS mentioned earlier is being considered in improving the operational agrometeorological advisory services across the world.

\section{Ground data used in GIS application}

Under the GKMS project, GIS is used extensively by utilising the weather information from the conventional as well as the automatic weather stations (AWS) including crop state and stage, soil information pests and diseases, and so on. The information/products so far obtained are 

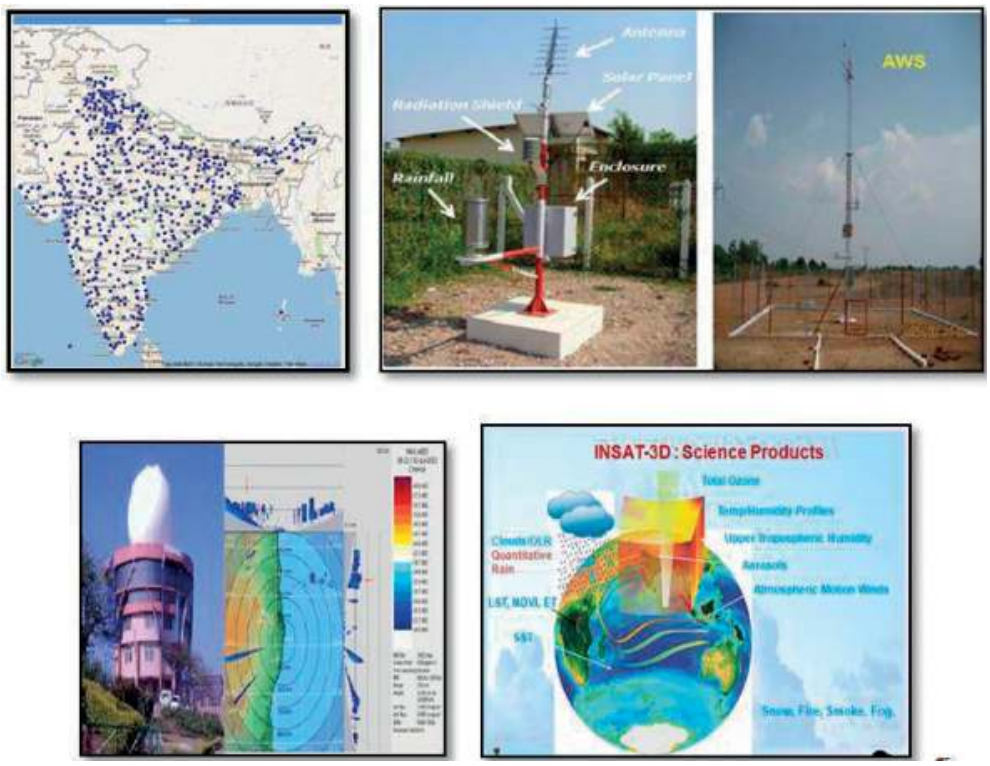

Figure 1. Observational network of IMD.

utilised at the time of sowing of crops, irrigation scheduling, fertiliser application, pesticides application, and so on.

IMD is establishing a number of observatories like surface, agromet, and so on to provide operational and R\&D on atmospheric sciences. IMD is having different kinds of networks of observatories in India to monitor and assess the extreme events which are conventional observational network, automatic weather stations (AWS), buoy/ship observations, cyclone detection radars, Doppler weather radars and satellite observations. Satellite and radar observations are very crucial for monitoring and assessment of hazards, especially the Himalayan region and North Indian Ocean.

Figure 1 shows the weather observational network in India. At present, there are surface (532), automatic weather stations (593), automatic rain-gauge stations (1352), agromet observatory (264) and DRMS (3500). Maintenance and strengthening of atmospheric observational network is absolutely required to sustain and improve the skill of weather forecasts. IMD has been augmenting its observing system networks over the past years. At present, geospatial technology is used to convert discreet data into continuous data. Using interpolation technique, the data are converted to spatial spread. These data cover each and every district of India at a high-resolution scale which can be used for the betterment of agro-advisory.

\section{Use of GIS in agrometeorological products in India}

At present, under the GKMS project, extensive data on crop, weather and satellite data are being used to prepare the advisories at different temporal and spatial levels. In view 


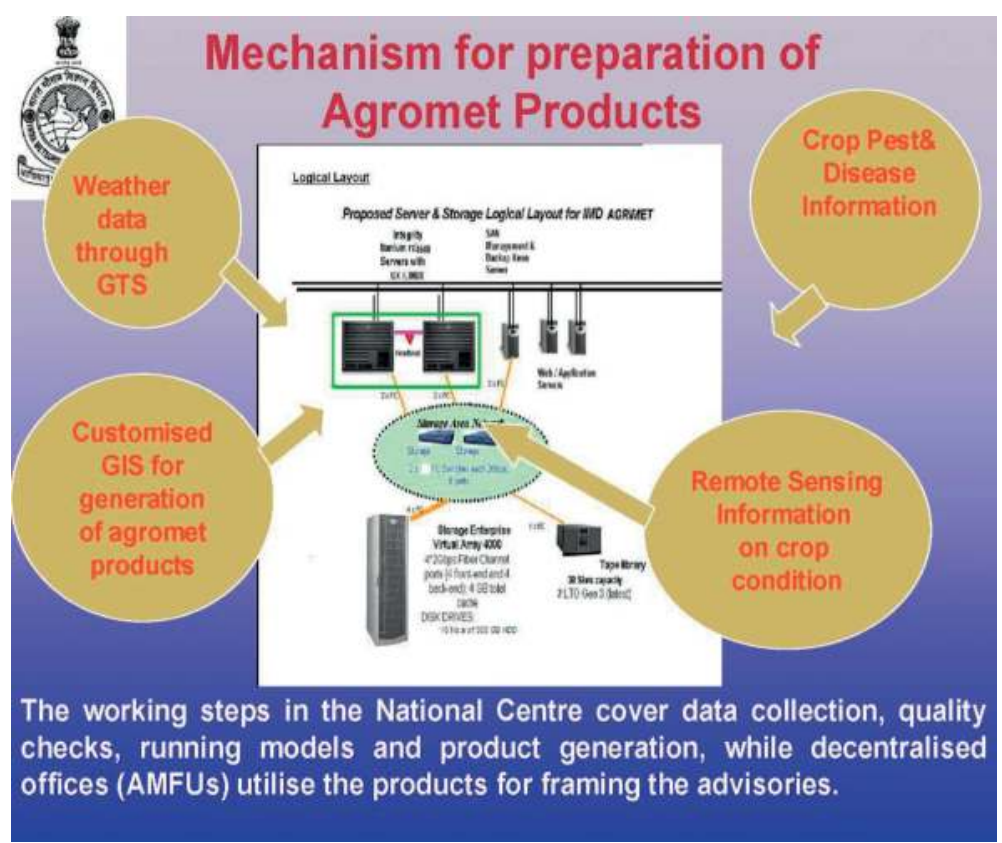

Figure 2. The mechanism for the preparation of agromet products.

of that, geospatial technology is being used in generating a number of products using ground-based data as well as the satellite data. To provide these services on a pan India mode, station-wise point data are not enough to generate the required products at the desired level. The present system helps IMD to compile data from various monitoring stations, analyse, generate advisories and disseminate information through online in near real-time basis. Since information is broadcasted in the form of maps and tables, it also helps users to extract various advisories and other information specific to the location of interest. Under the present system, it is possible to compile meteorological data from various monitoring stations along with geographic data from other sources, analyse, generate maps related to weather information, hydrology, agromet advisories, and so on and disseminate information through state-of-art communication system in near real-time basis. Since information will be broadcasted in the form of map and tables it helps users to extract various advisories and other information specific to location of interest. The software accommodates various algorithms and models to generate agromet, climatological and hydrological products.

It covers the following aspects:

- study of existing data including maps,

- preparation of guidelines for data standards and formats to be followed,

- preparation of mechanism to collect data/information from various field stations and linking with decision support system (DSS), 
- study of interpolation techniques to be used,

- study of algorithm for agromet advisory.

The digital data are being collected from different authorised agencies through IMD for the preparation of digital database. The mechanism for the preparation of agromet products is given in Figure 2.

\section{Product generations from the ground observations using GIS}

In the context to the Indian agriculture, advisories have been given to farmers using weather information at the district level. Weather information and their departure from normal value at different temporal and spatial scales are useful for the preparation of agromet advisories. In view of that, daily, weekly, fortnightly, monthly and seasonal contours (Figure 3) are being generated utilising the realised weather observations for the parameter temperature (maximum temperature, minimum temperature and diurnal temperature variation), maximum and minimum relative humidity, cloud and wind speed. Synoptic observatory data received through Global Telecommunication System (GTS) are used to generate contours on a pan India mode. Weather information and their departure from normal value at different temporal and spatial scale is useful information for preparation of agromet advisories. In view of that daily, weekly, fortnightly, monthly and seasonal contours are being generated utilising the realised weather observations for the parameters temperature (maximum temperature, minimum temperature diurnal temperature variation), maximum and minimum relative humidity, cloud and wind speed. Synoptic observatory data received in GTS is used to generate contours on pan India mode. Using GIS software, the data are converted to spatial spread.

\subsection{Daily spatial rainfall}

Gridded rainfall data generated daily over India at a grid resolution of $0.25^{\circ} \times 0.25^{\circ}$ of measured rainfall from the large number of rain-gauge stations distributed over India are interpolated using IDW interpolation at $0.25^{\circ} \times 0.25^{\circ}$, and the spatial district rainfall is generated using GIS software. The daily spatial rainfall maps are given in Figure 4.

\subsection{Realised and forecast soil moisture on a pan India mode}

The daily soil moisture (Figure 5) has been computed by soil water balance (SWB) based on the method given in Ref. [6]. The spatial district rainfall values extracted in GIS are used as data source to generate the daily realised soil moisture using SWB model. Soil moisture generated from SWB model is further interpolated using Gaussian interpolation technique under Krigging to generate spatial soil moisture maps. In addition to daily soil moisture data, the cumulative difference between two consecutive days for soil moisture is also made using GIS software. Dynamic potential evapotranspiration (PET) computed from Indian Geostationary Satellite (INSAT 3D) interpolated in GIS is used in this model. 


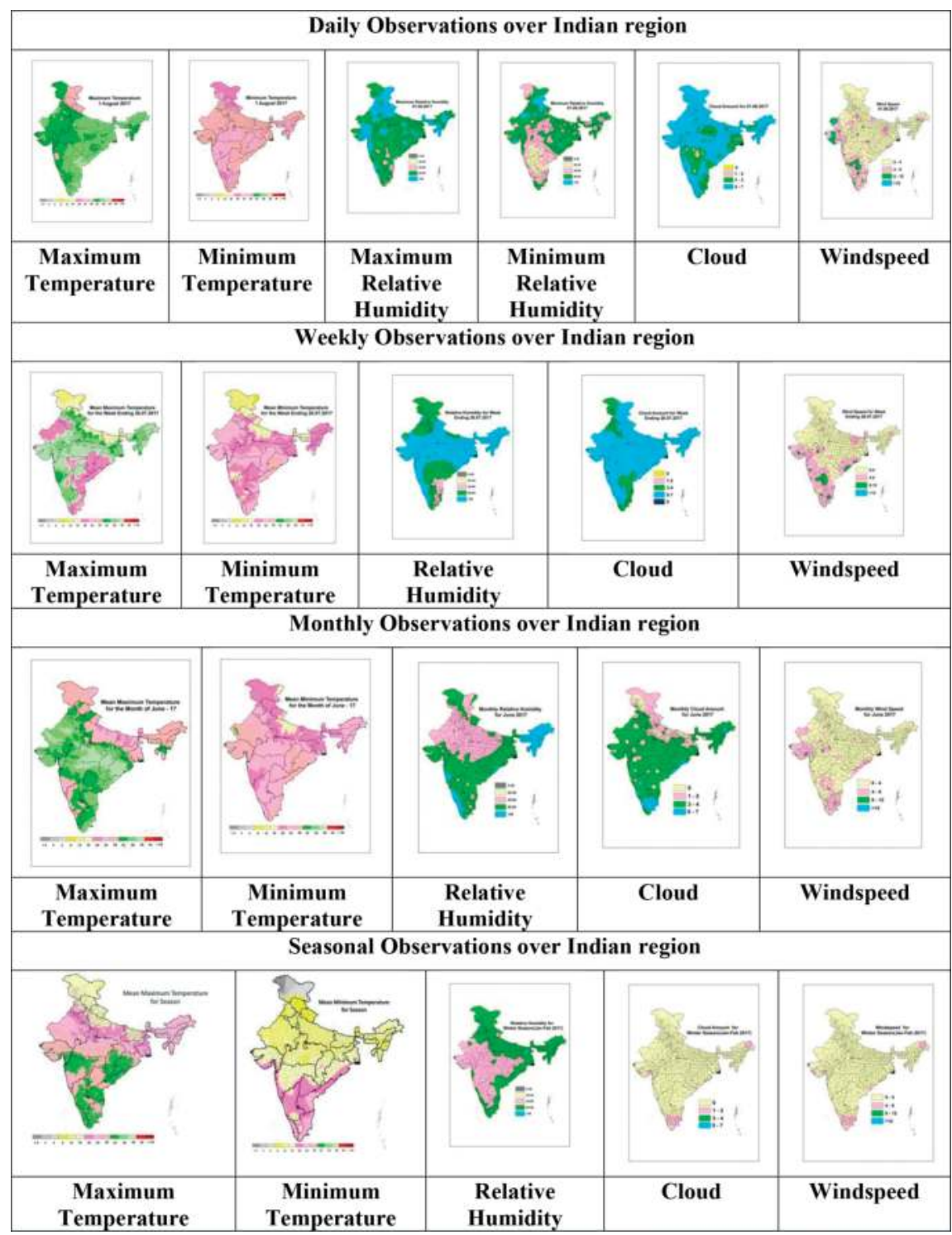

Figure 3. Spatial spread of daily, weekly, monthly and seasonal weather parameters over India.

Soil moisture forecast (Figure 6) is made based on the quantitative rainfall forecast (NWP model output of T 1534). NWP model output (rainfall) values added by different Regional Meteorological Centres/Meteorological Centres of India on every Tuesday and Friday are being used as district level rainfall in SWB model to generate soil moisture forecast. 

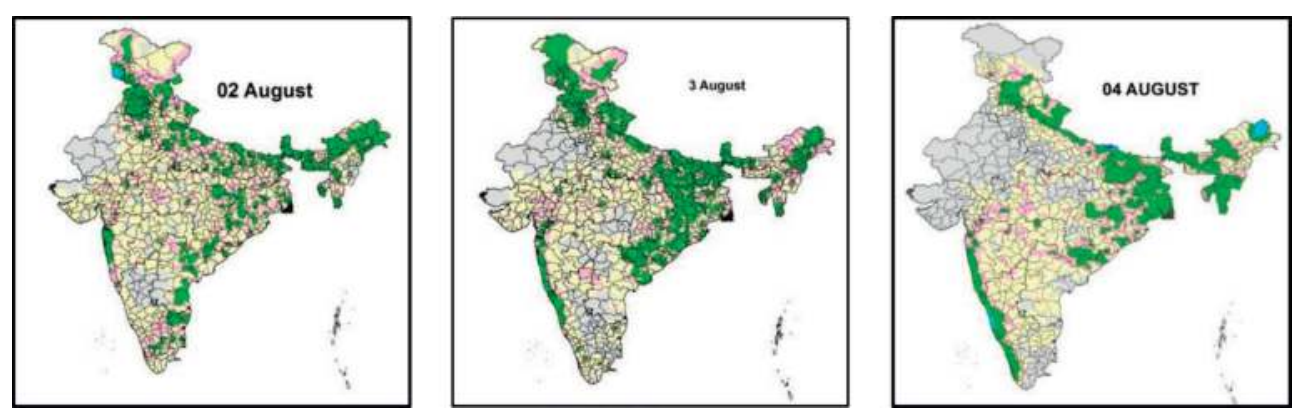

Figure 4. Daily spatial rainfall.

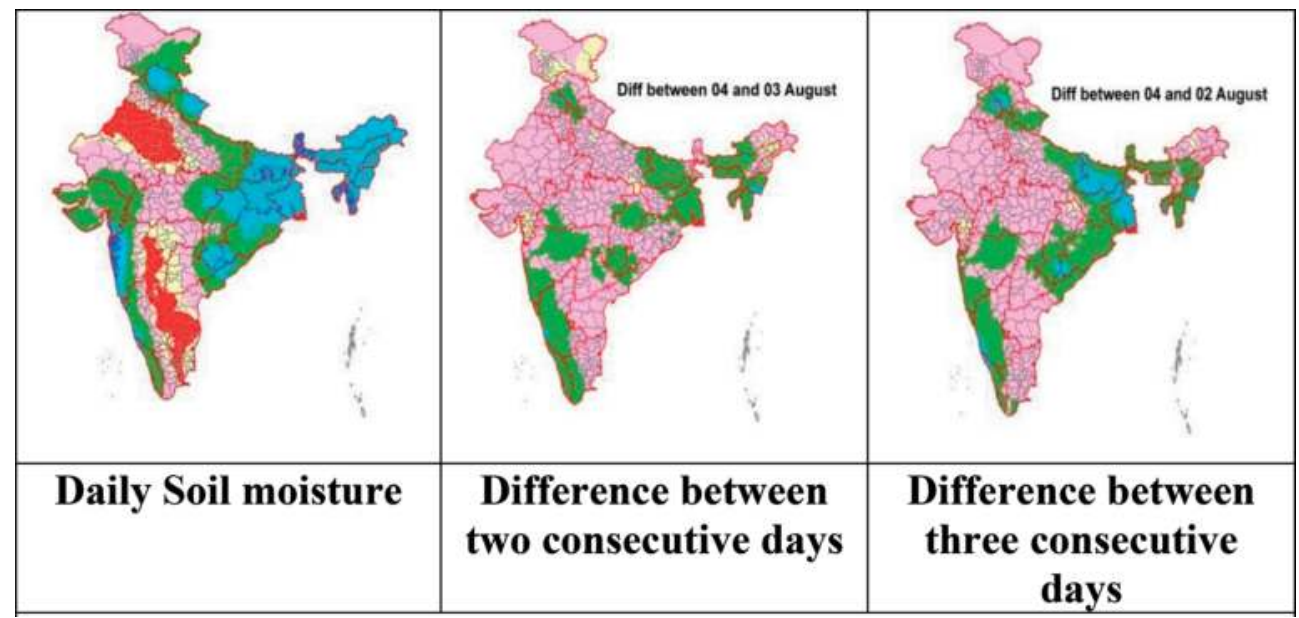

Figure 5. Realised soil moisture on a pan India mode.

\subsection{Soil temperature and its anomaly at different depths}

Presently, 153 stations are recording soil temperature at different depths at 07 LMT and 14 LMT. Soil temperatures recorded at these stations are used for spatial spread on a pan India mode using GIS software at different depths $(5,10$ and $20 \mathrm{~cm})$ which are depicted in Figure 7.

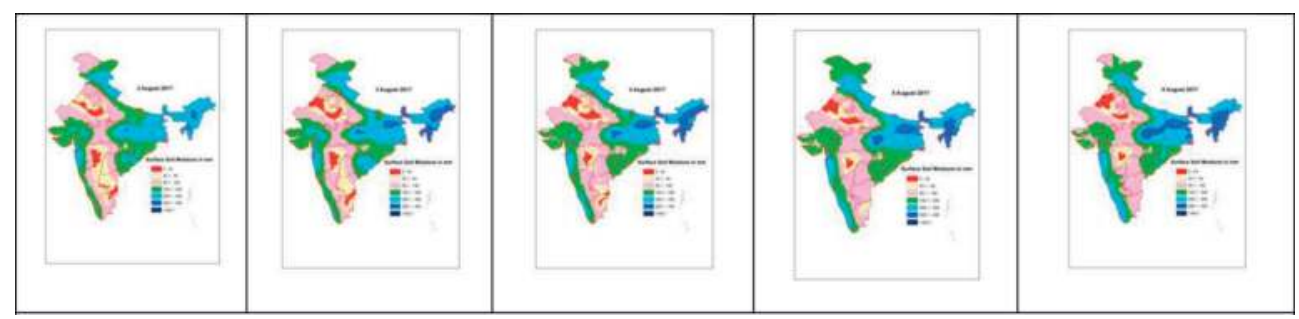

Figure 6. Forecast soil moisture on a pan India mode. 


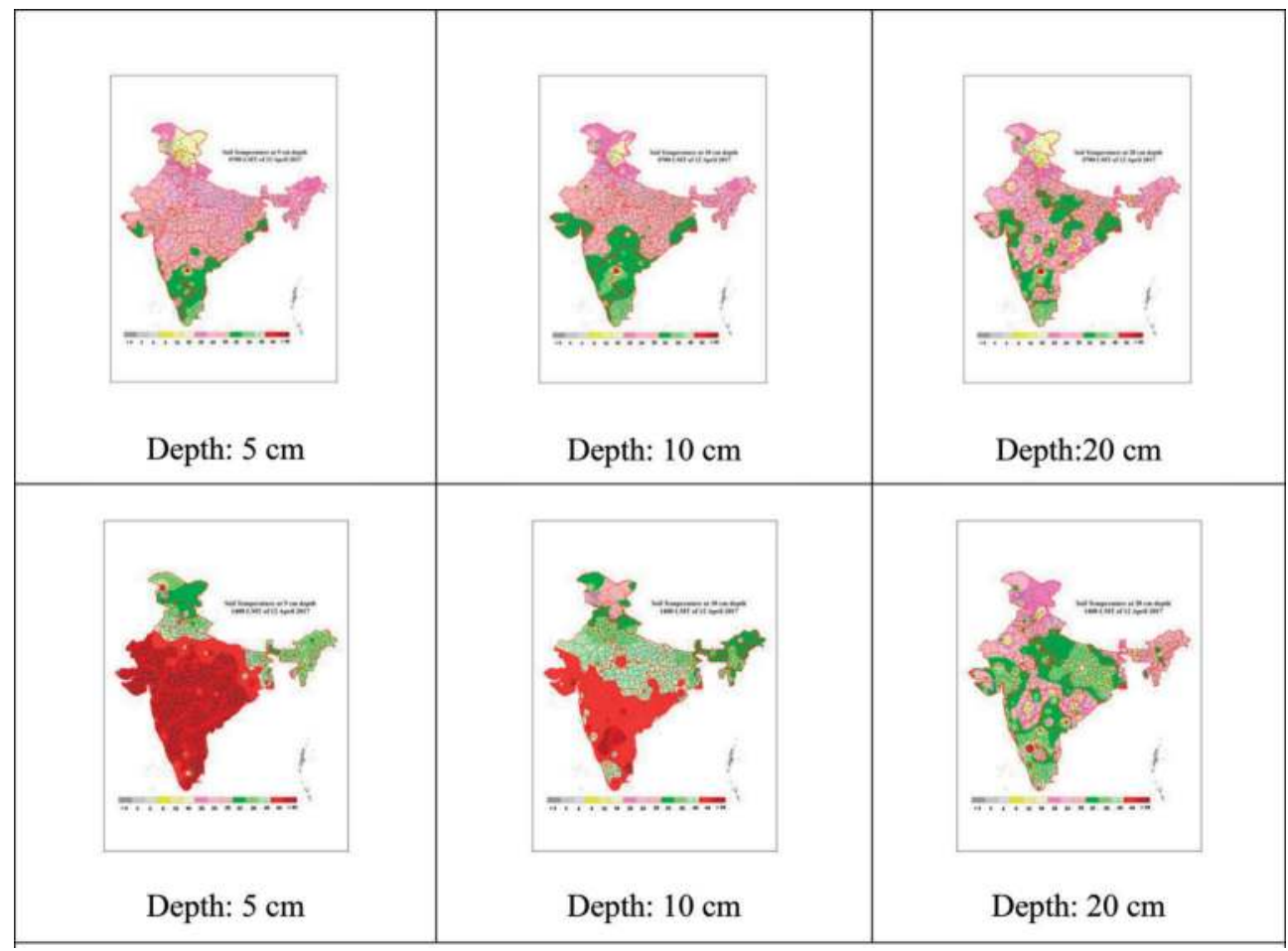

Figure 7. Soil temperature and its anomaly at different depths.

\section{Web-GIS-based spatial decision support system development}

An interactive web-GIS-based spatial decision support system (SDSS) is being developed to cater to various requirements of IMD in the field of agriculture, hydrology, weather forecasting, pest and disease forecasting. This software has the facility for digitisation, editing, interpolation and advisory generation and dissemination. The system has the following modules:

a. spatial database generation.

b. weather information map preparation,

c. hydrological analysis,

d. agromet advisories preparation.

The details of the modules are mentioned as follows:

a. Spatial database generation

This module has tools for 
- digitisation of point, line and polygon feature,

- editing of digitised features,

- entry of attribute (non-spatial) information,

- linking of external non-spatial data,

- data import/export,

- linking of GTS (global telecommunication satellite) data with GIS.

b. Weather information map preparation

This module includes tools for

- generation of forecast maps based on forecasts/warnings issued for various weather parameters like rainfall, temperature, and so on,

- generation of weather anomaly maps (pressure, wind, temperature (maximum, minimum and dew point) and extreme meteorological event maps like heat wave, cold wave, etc.),

- generation of climatological maps of rainfall, maximum temperature and minimum temperature all over India.

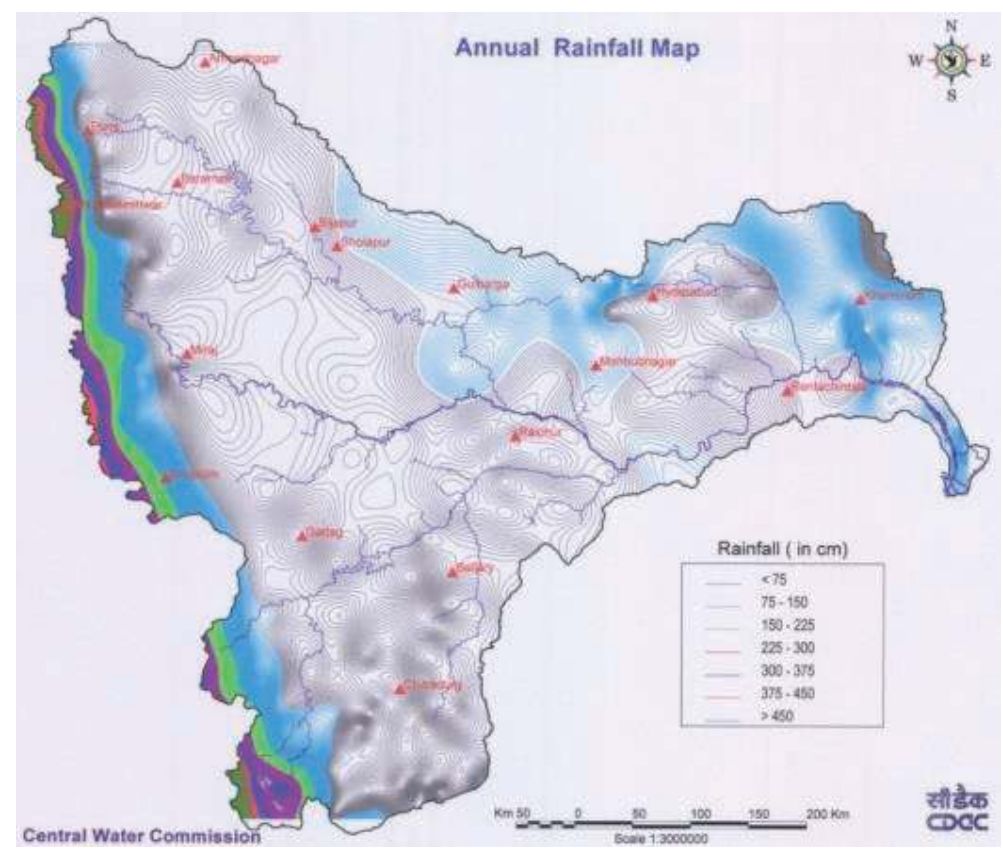

Figure 8. Annual rainfall map (with Isohyet) of Krishna Basin. 


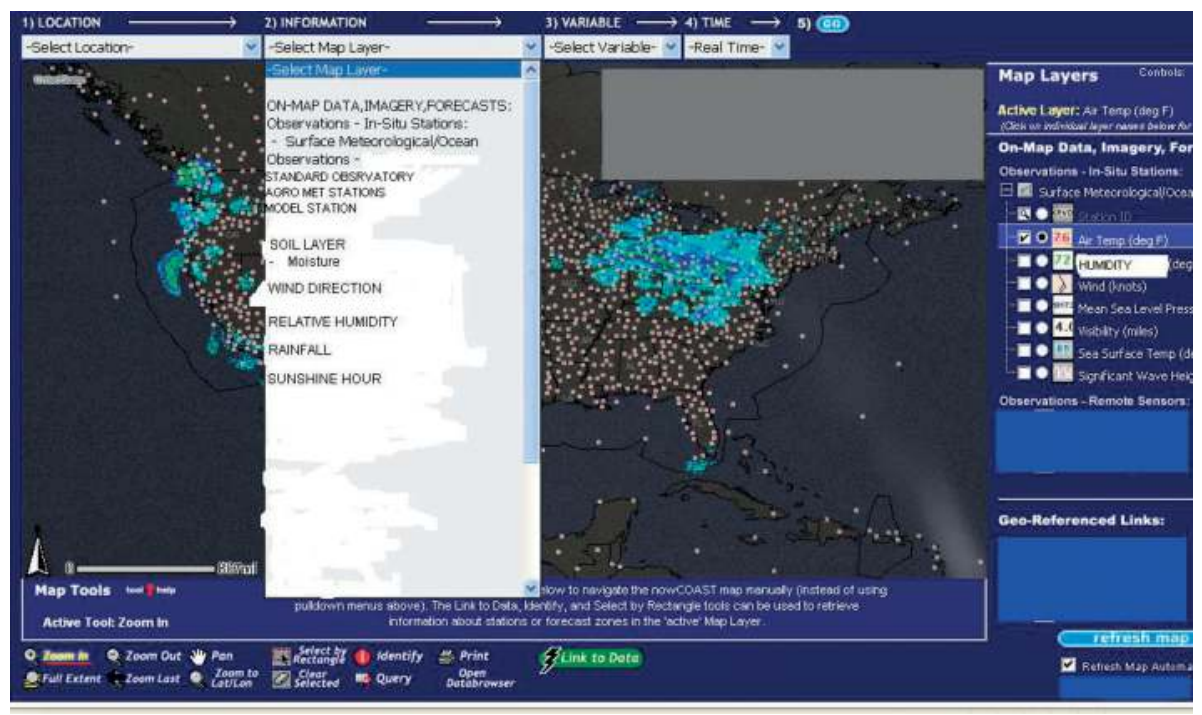

Figure 9. An example of an interactive web-GIS portal.

c. Hydrological analysis

This module includes tools for

- importing point data such as rainfall, temperature, relative humidity, and so on, with respect to geographic locations,

- interpolation of point data to generate surface map of rainfall, temperature, and so on,

- generation of isoline maps: this tool is used to generate isolines of different weather parameters like temperature (isotherm), and so on as shown in Figure 8.

d. Agromet advisory preparation

This module includes tools for

- Field data entry: a form is designed to facilitate field station user to enter field data such as crop, crop condition, soil moisture, location, and so on.

- Importing field data from the data entry form.

- Map generation for parameters like soil type, soil moisture, soil temperature, air temperature, humidity, rainfall, wind, cloud, bright hours of sunshine, crop condition (biotic and abiotic stress) and pest-disease infestation status, drought and aridity along with textual and data information.

- Generation of real-time agromet products (crop and location specific) like pest forecasting, irrigation scheduling, fertiliser application, and so on, using requisite meteorological 
data, crop data and soil data. Preparation of agromet advisories (crop and location specific) for different agro-climatic zones (a total of 127) in the country addressing to intrazonal variability at the district level (about 640).

e. Data collection and organising

- Accuracy check: the accuracy of the individual map will be assessed in terms of topology, digitisation error and attribution.

- Map projection: all collected maps will be brought into a standard projection system as per the SRS.

- Mosaicking and edge matching: the individual map with a desired accuracy will be processed further for edge matching and mosaicking to prepare seamless datasets.

- Data attribution: each feature of the digitised map will be linked with its attribute data.

Figure 9 depicts an example of an interactive Web-GIS portal for operational agrometeorology.

\section{Application of GIS in product generation with satellite observations}

As climatic variability and climate change will shortly throw huge challenges to agricultural productivity and agricultural production in the country, the days are not very far that farmers of the country will need personalised services on their farm management. Here, remotesensing/satellite information will play a great role when the country does not have an ideal network of weather observatories, or if at all there will be more observatories, it will take more number of years and the management of weather observatories will also be a herculean task for a country like India. Satellite offers a unique source of information for many agricultural applications. Recent advances in satellite technology in terms of high-resolution, multi-spectral bands provide useful information for agricultural operations. The integrated use of satellite data and conventional meteorological observations are found to be very useful to extract information relevant to agriculture in India. Agricultural meteorology is one of the fields of hydrometeorology for which satellite data are very important. Agrometeorological parameters are very variable in time and space. Ground observations do not provide end users with the required spatial and temporal resolution. Figure 10 shows the current Indian Geostationary Meteorological Satellite. Information about large areas can only be obtained by remote-sensing. The flow of data from new satellites such as Meteosat-8, Terra, and so on is much more informative which opens new areas for agrometeorological applications. Satellite remotesensing technology is increasingly gaining recognition as an important source of operational agrometeorological services. The regular and national-scale agrometeorological monitoring of the physiological processes and growth indicators require the retrieval of basic land surface variables using spatial observations. The challenge for research therefore is to develop new systems extracting this information from remotely sensed data, giving to the final user's nearreal-time information. Satellite-based agrometeorological products and the interpretation of 


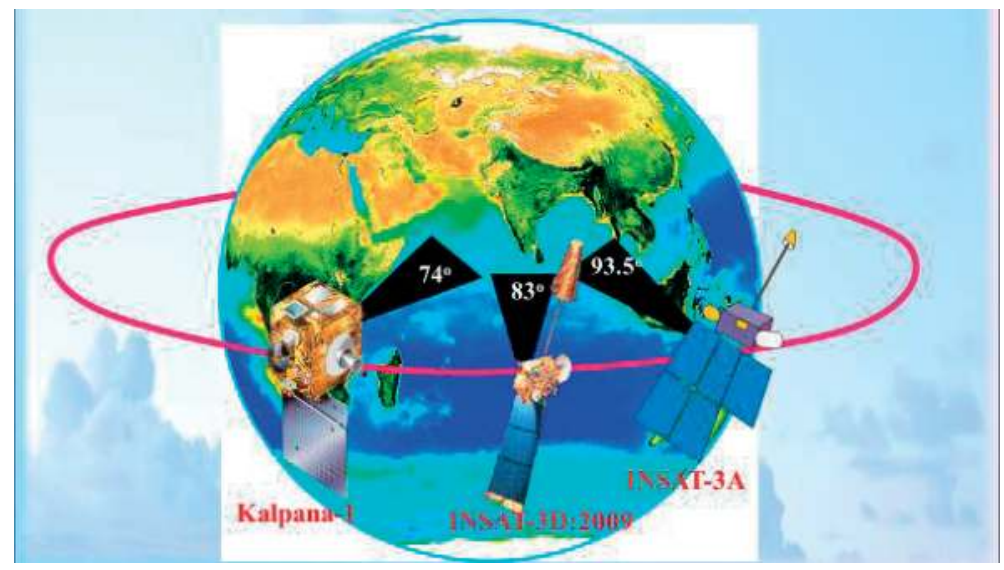

Figure 10. Current Indian geostationary meteorological satellites.

the same in terms of crop and soil moisture status will help the experts to frame the advisories in a better way and ultimately improve the quality of the advisories. In order to extend the support of the ongoing operational AAS, the generation of satellite products for the generation of location-specific agromet advisories is required to meet the end-user requirement.

Besides, the remote-sensing technology helps to provide information for monitoring the pest and disease, drought and flood conditions along with the remedies to the farming community before the situation turns into a disaster affecting the crop yield and productivity. The potential zone for agriculture activities can be identified by studying the climatic variability, and localised services may be provided to the farmers to increase productivity. The yield productivity can be estimated using the remote-sensing technology where information can be further used for the crop insurance services. Remote-sensing methods can be integrated with crop growth models and statistical models to estimate better result in a spatial format. The great challenges would be to the meteorologists/agrometeorologists and space scientists to develop bias-free meteorological/agrometeorological information at its proper application at a local scale to further increase agricultural production to the huge population of the country in the coming years. In order to provide high-resolution information at a ground level, it is almost mandatory to use the remote-sensing data into the GIS hub under the advanced operational Agromet Advisory Services. At present, utilising the information of geostationary and polar satellite, a number of information like soil moisture index, land surface temperature (LST), Normalised Difference of Vegetation index and vegetative condition (VCI) are used to generate a number of information particularly when the plants are in stress conditions.

All information produced by the satellite is elaborated for the extraction of the desired information. There are many methods, algorithms and procedures to derive fundamental data for agrometeorological application from remote-sensing. Among the existing indices, the most extensively used are the land surface temperature (LST) which is a good indicator of climatic and microclimatic conditions prevailing close to the surface, as well as the frost or the moisture in the soil. 
In developing countries, GIS use can be promoted through the transfer of technologies and information from the developed ones. This requires generalisation of the knowledge and studies carried out elsewhere. Moreover, frequently in developing countries, data used for the production of the informative layers are often unreliable or even lacking. Besides, the models used in these systems are the results of studies and projects, realised at different scales. Implementation of a GIS requires a great effort to collect and organise the available information on the territory. This important activity requires a period of validation for the operational use of the system. In any case, many projects have started to implement GIS in a number of different environmental and economic systems, mainly using information derived from remote-sensing to complete the direct observations. The common advantage is the definition of the state of the art and a first study of the particular problems, with the suggestion of innovative specific solutions. At this level, the products often are already used for practical applications, and the operators find it sufficiently powerful and reliable.

The data collected and the different information layers are organised in a database, and all the information about the territory is integrated in a GIS. Each layer is composed of different archives (numeric data, text and images), which were preliminarily controlled and evaluated. The archives are completed with graphical representations of the main data trends and synthetic information, obtained by means of spreadsheet and statistical software. The most important information is extracted to describe the territory and then combined for understanding the possible relationships between the different factors. The representation of these data can be made for discrete or continuous values, to obtain thematic maps or territorial representation of the spatially distributed parameters. Satellite data are for agricultural monitoring as monitoring land condition and also for within-season forecasting.

Under GKMS project in India, a joint initiative has been taken up by the Indian Space Research Organisation (ISRO), Indian Council of Agricultural Research (ICAR), India Meteorological Department, National Centre for Medium Range Weather Forecasting (NCMRWF), Noida, Mahalanobis National Crop Forecasting Centre (MNCFC), New Delhi, under DAC (Department Agriculture and Cooperation) to prepare a roadmap for using satellite-based information to augment services to farmers. The ISRO centres include Space Applications Centre, Ahmedabad, National Remote Sensing Centre, Hyderabad, ISRO HQ, Bangalore, Indian Institute of Remote Sensing, Dehradun, and ICAR. With the launching of INSAT 3D, it is expected that Agromet Advisory Services would be further strengthened by providing customised information to the farmer at smaller areas.

A number of studies are being made with the geostationary satellite launched in India, that is, INSAT 3D. INSAT 3D has two kinds of payloads 'Imager' and 'Sounder'. The 'Imager' has six bands consisting of broad visible (VIS), short-wave infrared (SWIR), middle infrared (MIR), water vapour (WV) and two split-thermal infrared (TIR) bands. The optical (VIS, SWIR, MIR) and thermal bands (TIR) from 'Imager' are able to capture reflective and emissive signatures in cloudless skies at half-hourly interval with a single snapshot over the entire country and South-East Asian continent. The combination of all these products from 3D, improved weather forecasts, vegetation index product from INSAT 3A CCD and in situ data are valuable ingredients to generate real-time value-added information for enhanced operational agromet advisory services in the country. The long-term datasets from INSAT suite will be able to aid in 
digital agro-climatic characterisation. A large scope of advanced research exists to explore the INSAT data, to develop advanced algorithm, to improve the accuracy of scheduled product and develop new products. The Imager data would be able to provide satellite meteorological (sat met) products such as rainfall, land surface temperature (LST), land surface albedo, incident solar radiation, cloudiness, upper troposphere humidity (UTH) and outgoing long-wave radiation (OLR). The occurrence and progress of fire, fog and smoke can also be monitored by INSAT 3D data. IMD and SAC have jointly started the incorporation of satellite-based agrometeorological component, particularly NDVI composite image, developed from INSAT 3A CCD image for generating information on crop vigour and agricultural progress. This information along with the rainfall data are being used in stress monitoring and track the crop growth from sowing to harvesting of the major crops in the country. Besides, some studies on crop stress detection through the estimation of evapotranspiration using satellite data have also been attempted in the past along with pest-disease studies based on weather and satellite data.

It is planned for the effective usage of satellite observations, particularly Indian satellites, to improve the initial conditions of Numerical Weather Prediction (NWP). The Research and Development (R \& D) activity for the optimal use of the satellite data is being carried out,

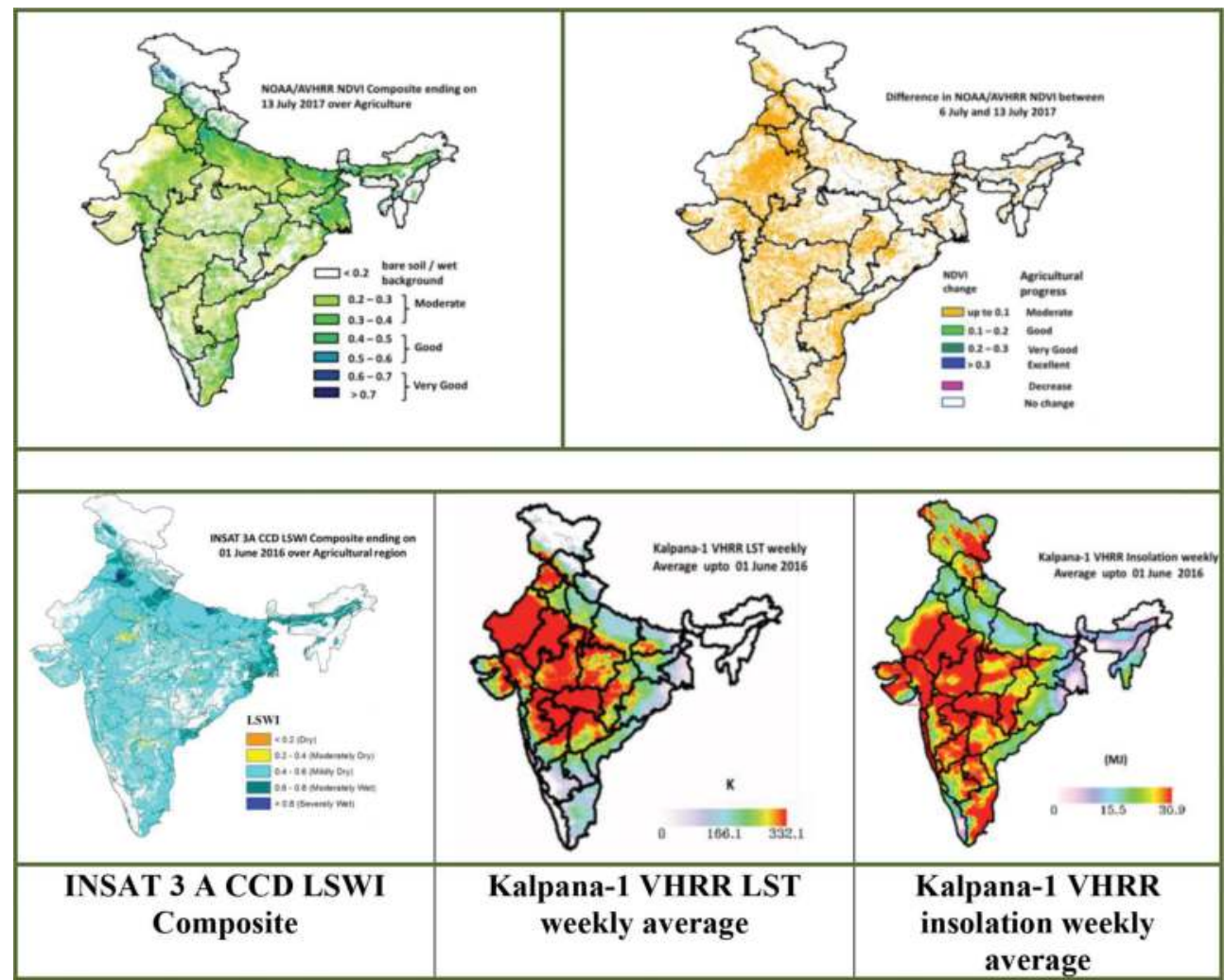

Figure 11. NOAA/AVHRR NDVI composite and difference. 
and subsequently, improved assimilation system for the optimal use of the satellite is implemented. The implementation plans are given as follows:

- Operationalise the assimilation of SAPHIR and INSAT-3D radiances in the Multi-Model Ensemble (MME) for improvement of weather forecast.

- Assimilation system to assimilate different land surface products such as soil moisture, vegetation and snow fraction, land surface temperature and albedo.

- Development of RAPID system (www.rapid.gov.in). This system is a geoportal for satellite meteorology and forecasts with different Web-GIS facilities. This system should be modified and adapted for agrometeorological applications and agro-advisory purposes so that any official engaged in Agromet Services can utilise this facility.

The data from suite of INSAT satellites are being received and processed on real-time basis through an operational chain known as INSAT Meteorological Data Processing System (IMDPS), New Delhi, as well as mirror site in IMDPS, SAC, Ahmedabad. The images and digital products at different time scales (half-an-hour to daily) from IMDPS on real-time basis have great potential for use in the preparation of advisories for Agrometeorological Services on an operational basis and ensuring the availability of data on a requirement basis.

There are specific requirements to derive some specialised products such as surface insolation, LST, albedo and reference evapotranspiration from INSAT 3D 'Imager'. It is proposed to develop algorithms of all these products and will be implemented at IMDPS, New Delhi, for generation of these products on an operational basis. Validated global 7-day composite of

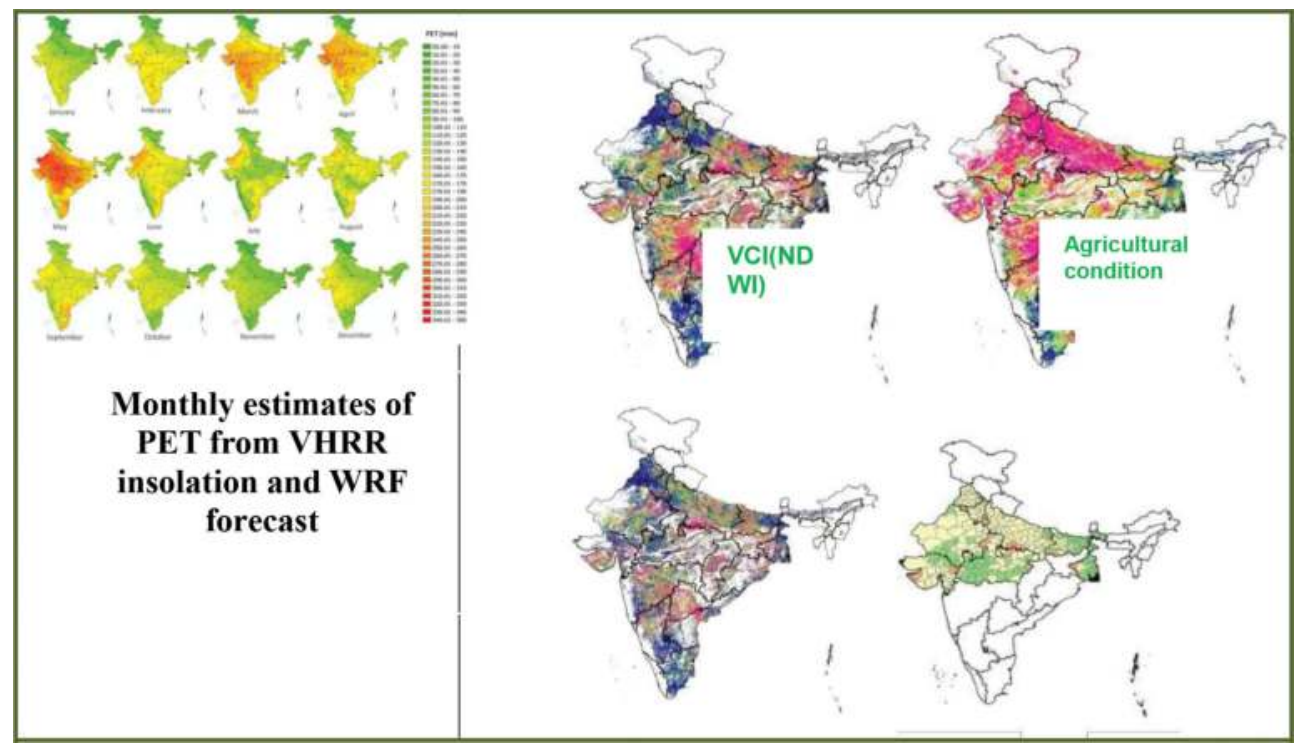

Figure 12. Different remote-sensing products. 
SMN data at $4 \mathrm{~km}$ is derived from no noise NDVI (Normalised Difference Vegetation index). Gridded weekly global vegetation indices (SMN, VCI, TCI and VHI) are derived from NOAA VHRR satellites. These datasets can be used to estimate the vigour and stress on vegetation, start of growing season and its phonological phages. Weekly NDVI products and composite maps are being operationally generated for the Indian region (Figures 11 and 12).

In order to provide large-area updates by using finer-scale low-repeat RS data and products over land, data from IRS, OCM, AWiFS, MODIS and RISAT-1 are being created weekly composite of vegetation indices, snow cover and snow/water fraction. Surface insolation and land surface temperature (LST) from INSAT 3D are being operationalised in India. Besides, efforts are being made to operationalise products of land surface albedo and reference evapotranspiration at IMDPS, New Delhi. The generation of potential crop maps for rice (kharif, rabi), wheat, mustard, cotton, potato, sugarcane, jute and rabi sorghum at 100-200 m spatial resolution all over India coverage for all the above crops once in a season is in process including advanced operational agromet products such as actual evapotranspiration, aridity index and water requirement satisfaction index (WRSI). These products are made available subjected to the success of other core agromet products to be generated from INSAT 3D. Different remotesensing products for agrometeorology are depicted in Figure 12.

\section{Other projects on use of satellite information in operational Agromet advisory services}

\subsection{Determination of soil moisture over India using space-borne passive microwave sensors on board SMOS}

Soil moisture is being estimated for three states, Uttar Pradesh, Madhya Pradesh and Gujarat (Figure 13), by the satellite products, namely SMOS (soil moisture and salinity) launched by European Space Agency (ESA), MODIS (NDVI and LST from Terra/Aqua) and SSMIS (Special Sensor Microwave Imager/Sounder) by NASA for (LST) using Beam 4.9 software.

Satellite data-based fusion approach to develop soil moisture monitoring system in India: Methodology has been developed for the estimation of soil moisture using SAR data from PALSAR (phase array L-band synthetic aperture radar) and NDVI from MODIS using NEST and POLSAR-PRO software. On experimental mode, soil moisture maps have been generated in Moga, Hissar, Roorkee, Saharanpur, Meerut, Dhanbad and Moradabad with the resolution of $25 \mathrm{~m}$.

\subsection{Optimum sowing suitability for kharif (June and July), rabi (November and December) seasons and general agricultural health based on edaphic factors}

Activities on the use of satellite data have been initiated in collaboration with different organisations (Space Applications Centre, ISRO), to strengthen the Agromet Advisory Services (AAS). One important activity, that is, sowing suitability of crops during kharif season, has been started using the satellite data (AMSR-2 (Advanced Microwave Scanning Radiometer sensor), soil moisture content (SMC at $10 \mathrm{~km}$ available from Japan Aerospace Exploration 

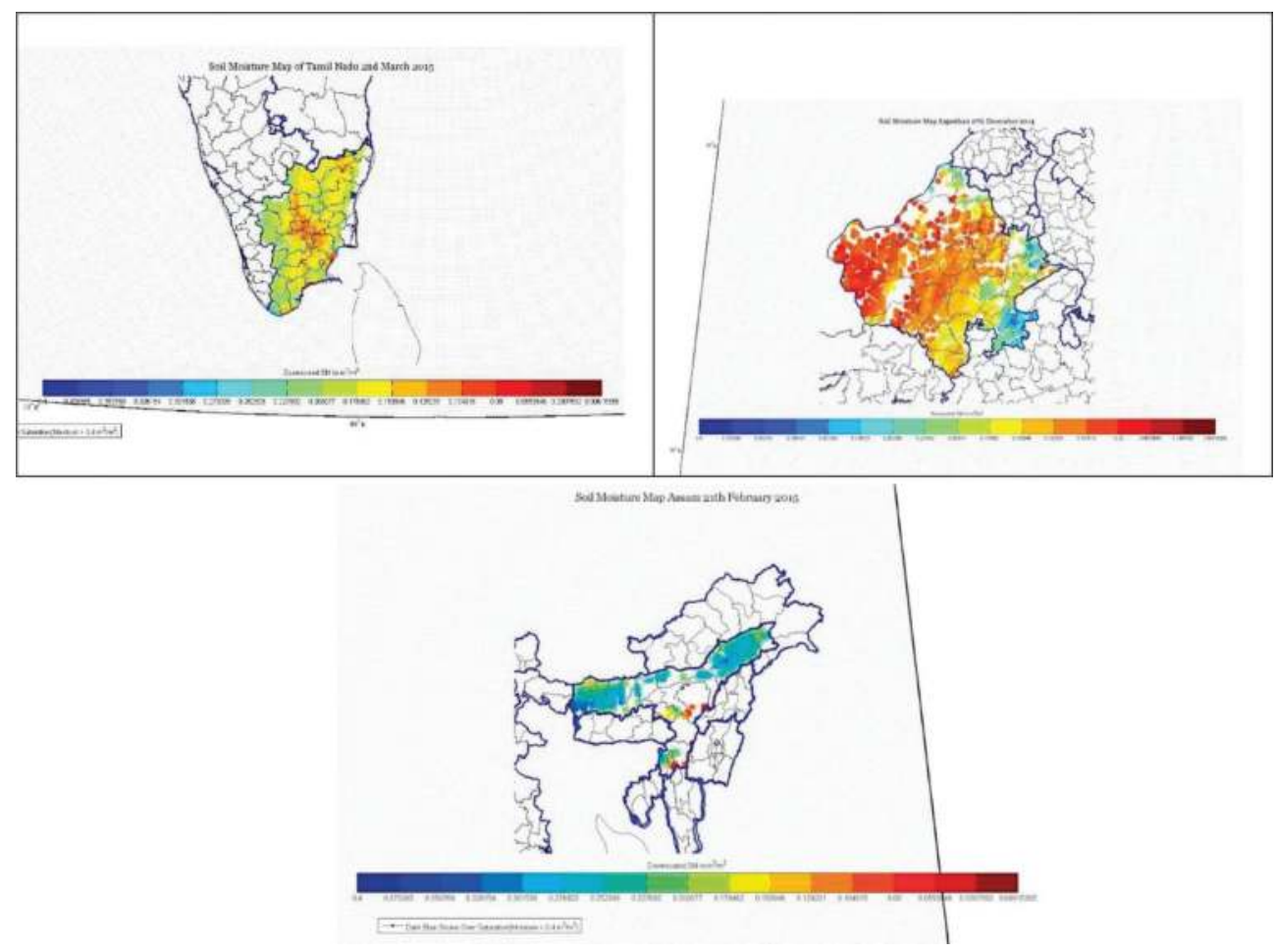

Figure 13. Estimation of soil moisture using SMOS.

Agency) and (Indian Geostationary satellite) INSAT 3A CCD NDVI (1 km) data). In order to provide large-area updates, the weekly mean of AMSR-2 surface soil moisture (SSM) and the weekly composite of INSAT Normalised Difference Vegetation Index (NDVI) are used. The geospatial integration of these two was carried out after putting desired thresholds. It is known that the optimum surface soil moistures of $0.1-0.15 \mathrm{~m}^{3} \mathrm{~m}^{-3}$ maintained at least for a week or 2 weeks are ideal at the start of the growing seasons if soil temperature and other meteorological conditions are conducive. Spectral emergence is evident when NDVI crosses 0.3. In kharif season, the weekly accumulated rainfall and their thresholds determine sowing. These thresholds vary from crop to crop and according to different agro-climatic settings. Using this information, the current week and the previous week SSM were applied a threshold of 0.1-0.15 and the current week NDVI was applied a threshold of 0.3 to extract the area suitable for sowing. Further thresholds were applied to determine the already sown area. The maps in Figure 14 show the sown area and area conducive for sowing. The corresponding weekly rainfall maps also show the area with normal or excess rainfall in two consecutive weeks that are probably sown or conducive for sowing.

Presently, the satellite and modelled rainfall maps are the source used for the prediction of area suitable for sowing. The abovementioned maps, which use the soil moisture condition and vegetation 

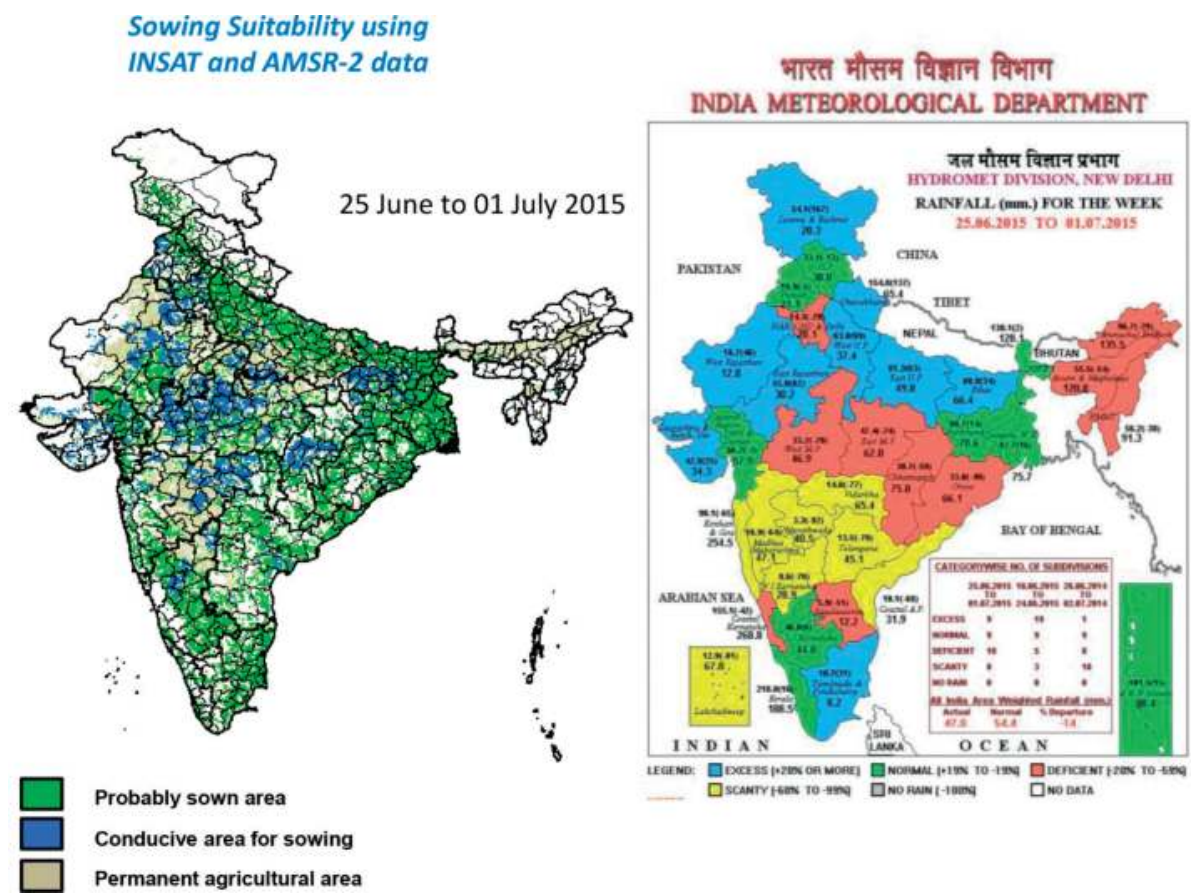

Figure 14. Sowing suitability map.

condition, can act as promising maps for prediction areas suitable for sowing. The technique to generate this map has been prepared and the satellite data used can be made available freely. Thus, this methodology to generate sowing suitability maps can be made operational and can be shared with different AMFUs by providing state-level sowing suitability maps.

\subsection{Development of methodology for forecasting spatial crop age/phenology}

Response to abiotic stresses and quality of advice to farmers depends on the crop type and crop growth stages. The crop age or phenological stages depend on spectral emergence date/ sowing date and subsequent ambient temperature and sunshine hours expressed through thermal and helio-thermal units. The length of the growing season is determined from spectral emergence date and the date of physiological maturity.

Temporal profiles of vegetation index from satellite remote-sensing observations are modelled to trace back spectral emergence date. Early detection could be possible if high temporal vegetation index with a resolution varying from 200 to $1000 \mathrm{~m}$ depends on the crop type and coverage. The potential crop mask is an essential input to this. This work is being attempted for six major crops for which the potential crop masks are expected to be available. Superimposition of extended-range or medium-range weather forecasts with spectral emergence dates would provide crop age if agro-climatic zone-wise thermal thresholds are known. 


\subsection{Development and validation of crop water requirement satisfaction index (WRSI)}

Stage-wise crop water requirement satisfaction index is a function of potential, actual ET and crop age. This determines the level and persistence of water stress. The development of WRSI from available ET products from MODIS/INSAT or other sources is made for rabi crops such as wheat, mustard, potato and rabi rice. The validation is being carried out based on Eddy covariance, ISRO-AMS and scintillometer data available in India.

\subsection{Inter-comparison of different abiotic stress indicators}

Different satellite-based abiotic stress indicators have been reported over the past. These are Temperature Vegetation Dryness Index (TVDI), Vegetation Temperature Condition Index (VTCI), water deficit index (WDI), combined deficit index (CDI) and vegetation health index (VHI). These indices use various approaches such as triangle, trapezoid, lag correlation and anomaly that use satellite-based VI, land surface temperature (LST) and rainfall. Study is being carried out on comparing the efficiencies of these indices in both kharif and rabi especially over semi-arid regions or regions having history of persistent water scarcity such as Anantpur (Andhra Pradesh), Bundelkhand region (Uttar Pradesh), Saurashtra region (Gujarat) and Jodhpur-Jaisalmer region (Rajasthan).

\subsection{Development of digital agro-climatic atlas for improved crop planning}

The improved crop planning provides economic security to farmers. The improvement in crop planning for 'smart agriculture' depends on knowledge or information base from systematic historical data records on several agro-climatic databases valid for 127 agro-climatic regions. The long-term databases on satellite-based surface insolation, near-surface Tmax, Tmin, RHmax, RHmin, rainfall, LST, NDVI, $\mathrm{ET}_{0^{\prime}}$ AET, surface and root-zone soil moisture on monthly, seasonal and annual scales are generated after bias correction and temporal filtering at $5-10 \mathrm{~km}$. The ancillary databases on soil physical and chemical properties are superimposed. Geospatial analysis can be carried out to bring out national-scale digital agro-climatic atlas.

\subsection{Development of methodology for tracking of major pests and diseases}

The foremost step of spatial forewarning of pests and diseases is to obtain highly accurate and high spatial-resolution weather products. Different satmet products such as OLR, insolation, UTH, wind vectors and near-surface atmospheric temperature and humidity are available from IMDPS at a resolution varying from 5 to $30 \mathrm{~km}$. These data are being obtained at $30 \mathrm{~min}$ to $1 \mathrm{~h}$ temporal resolution. Some analysed fields are also being available. Standardisation of these satmet products or analysed fields with reference to in situ surface weather data will be carried out to adapt these to develop alarm zone for major candidate pests and diseases.

The work is initiated in mustard crop for Alternaria blight and Aphid, SATMET product (LST, $\mathrm{SpH}$ and sunshine hour/rainfall) near-surface $(2-3 \mathrm{~m})$ utilised for weekly progress of pest (incl. diseases) infestation, and then tracking the pest (incl. diseases) through a suitable growth model can be attempted. In this study, growth model is constructed for tracking of pest (incl. diseases) infestation on mustard crop with the combination of remote-sensing information. 
Hyper-spectral data using spectroradiometer in field and remote-sensing approach in reflectance for many continuous narrow wavelength bands in visible-near infrared (VNIR) and short-wave infrared (SWIR) region of electromagnetic spectrum are used for the detection and growth of Alternaria and aphid infestation in mustard crop within a year. Different spectral indices like NDVI, RVI, AI, SIPI, and so on are calculated for the identification of Alternaria infection and aphid infestation or stress on crop using remote-sensing.

\section{Conclusion}

Under the observed and projected climate change along with the climatic variability, productivity and production of major crops in India are expected to reduce substantially. Besides, weather and climate extremes during the last one and half decades damaged standing crops extensively. Under these scenarios, operational agrometeorological services play a great role. National Meteorological \& Hydrological Services in collaboration is another organisation providing services to the marginal and small farmers at present at the district level and shortly at the sub-district level for increasing the crop production.

Among others, the generation and use of different agromet information and products are important initiatives to deliver crop- and location-specific agromet advisories to the farmers in the country. Here, GIS has an important role to play. Agrometeorological products are derived parameters from meteorological/agrometeorological or other interdisciplinary information. At present, under the GKMS project, extensive data on crop, weather and satellite data are being used to prepare the advisories at different temporal and spatial levels. In view of that, geospatial technology is being used in generating a number of products using ground-based data as well as the satellite data. To provide these services on a pan India mode, station-wise point data are not enough to generate the required products at a desired level. At present, geospatial technology is used to convert discreet data into continuous data. Using interpolation technique, the data are converted to spatial spread. These data cover each and every district of India at a high-resolution scale which can be used for the betterment of agroadvisory. An interactive Web-GIS-based spatial decision support system is being developed to cater to various requirements of IMD in the field of agriculture, hydrology, weather forecasting, pest and disease forecasting. With the launching of a series of geostationary satellite, at present, vast information and products are available in India. The challenge for research is to develop new systems extracting this information from remotely sensed data, giving to the final user's near-real-time information. Satellite-based agrometeorological products and the interpretation of the same in terms of crop and soil moisture status will help the experts to frame the advisories in a better way and ultimately improve the quality of the advisories. In order to extend the support of the ongoing operational AAS, the generation of satellite products for the generation of location-specific agromet advisories is required to meet the enduser requirement. Under the operational Agromet Advisory Services, using GIS, a number of products like NDVI, VCI and PET (potential evapotranspiration) are being used to capture stress condition of crops for providing appropriate advisories. Besides, the generation of a number of information and products is in the pipeline. It is expected that with the ground data, satellite information and products and with the geospatial technology, more appropriate high-resolution and crop-specific agromet advisories will be provided in the near future 
and ultimately it will be possible to minimise the crop loss due to aberrant weather and also improve the economic conditions of small and marginal farmers in the country.

\section{Acknowledgements}

The authors are thankful to the Centre for Development of Advanced Computing (C-DAC), Pune, and Space Application Centre (SAC), Ahmedabad, for sharing the information in the preparation of this chapter.

\section{Author details}

Chattopadhyay Nabansu*, Chandras Swati and Tidke Nivedita

*Address all correspondence to: nabansu.nc@gmail.com

India Meteorological Department, Pune, Maharashtra, India

\section{References}

[1] Ballestra G, Bertozzi R, Buscaroli A, Gherardi M, Vianello G. Applicazioni dei sistemi informativi geografici nella valutazione delle modificazioni ambientali e territoriali. Milano, Italy: Franco Angeli; 1996

[2] Coulson RN, Lovelady CN, Flamm RO, Spradling SL, Saunders MC. Intelligent geographic information systems for natural resource management. In: Turner MG, Gardner RH, editors. Qualitative Methods in Landscape Ecology. New York: Springer Verlag; 1991. pp. 153-172

[3] Mueksch MC. Monitoring and assessing natural lake and environments for lake-GIS. In: Proc. GIS/LIS'96, Annual Conf. and Exposition, Denver, Colorado. 1996. pp. 30-36

[4] Bouman BAM, Nieuwenhuyse A, Hengsdijk H, Jansen HGP, Schipper RA. An integrated methodology for sustainable land use exploration using GIS. In: Proc. 1st Int. Conf. Geospatial Information in Agriculture and Forestry. Lake Buena Vista, FL, USA. 1998. pp. 230-237

[5] Taylor JD, Burger LW. Wild life habitat evaluation and planning using GIS. In: Proc. 1st Int. Conf. Geospatial Information in Agriculture and Forestry. Lake Buena Vista, FL, USA. 1998. pp. 215-220

[6] Thornthwaite CW, Mather JR. The Water Balance. Publ. in Climatology. Vol. 8, No. 1. Centerton, New Jersey: C.W. Thornthwaite \& Associates; 1955 